This item is the archived peer-reviewed author-version of:

Title: Electrochemical deposition of dodecanoate on lead in view of an environmentally safe corrosion inhibition

Authors: Karolien De Wael, Michel De Keersmaecker, Mark Dowsett, David Walker, Pamela

A. Thomas, Annemie Adriaens

In: J. Solid State Electrochemistry 14(3) (2010) 407-413

To refer to or to cite this work, please use the citation to the published version:

K. De Wael, M. De Keersmaecker, M. Dowsett, D. Walker. P.A. Thomas, A. Adriaens, Electrochemical deposition of dodecanoate on lead in view of an environmentally safe corrosion inhibition, J. Solid State Electrochemistry 14(3) (2010) 407-413.

\title{
Electrochemical deposition of dodecanoate on lead in view of an environmentally safe corrosion inhibition
}

Karolien De Wael ${ }^{\mathrm{a}}{ }^{1}$, Michel De Keersmaecker ${ }^{\mathrm{a}}$, Mark Dowsett ${ }^{\mathrm{b}}$, David Walker ${ }^{\mathrm{b}}$, Pamela A. Thomas $^{\mathrm{b}}$, Annemie Adriaens ${ }^{\mathrm{a}^{*}}$

${ }^{a}$ Department of Analytical Chemistry, Ghent University, Krijgslaan 281 S12, B-9000 Ghent, Belgium

${ }^{\mathrm{b}}$ Department of Physics, University of Warwick, Coventry CV4 7AL, UK

* Corresponding author. Tel: +32 926448 26; fax: +32 926449 60; email: Annemie.Adriaens@UGent.be

${ }^{1}$ Postdoctoral Fellow of the Research Foundation - Flanders (Belgium) 


\begin{abstract}
Non-toxic linear sodium monocarboxylates can be successfully used as inhibitors for the corrosion of many metals. The adsorption of these molecules onto a metal is usually achieved by immersing the metal in the carboxylate solution for a few hours. This paper describes the strength of cyclic voltammetry in forming a sodium dodecanoate coating on a lead electrode. We show that this approach is much less time-consuming compared to the immersion method, and enables one to control and to characterize the layer formed by following the potential and current during the process. Additional ATR-IR and X-ray diffraction spectroscopic analyses were performed to qualitatively characterize the newly formed coating.
\end{abstract}

Keywords: Lead; Carboxylate; Corrosion inhibition; Cyclic voltammetry; IR

\title{
1. Introduction
}

The corrosion of lead objects primarily depends on their surroundings, e.g. on environmental conditions. When buried in soil or exposed to the atmosphere, a stable corrosion layer (mainly composed of lead carbonates and lead oxides; e.g. cerussite and litharge) is formed, which, in general, protects the metal against further corrosion. However, lead artefacts can keep on corroding actively when stored in humid and organic acid atmospheres. Such circumstances often are created in wooden display cases, used in museums for storage or exhibition of art and archaeological objects [1].

A countermeasure for the latter has been found in the use of coatings deposited from solutions of saturated linear monocarboxylates of the type $\mathrm{CH}_{3}\left(\mathrm{CH}_{2}\right)_{\mathrm{n}-2} \mathrm{COONa}$, hereafter called $\mathrm{NaC}_{\mathrm{n}}$. In an initial study, Rocca et al. [2] showed that the protection is due to the growth of a crystalline lead monocarboxylate layer $\left(\mathrm{CH}_{3}\left(\mathrm{CH}_{2}\right)_{\mathrm{n}-2} \mathrm{COO}\right)_{2} \mathrm{~Pb}$, hereafter called $\mathrm{Pb}\left(\mathrm{C}_{\mathrm{n}}\right)_{2}$, which passivates lead surfaces and inhibits corrosion. The degree of inhibition depends on the carbon chain length and on the carboxylate concentration: higher chain lengths and higher concentrations commonly result in higher effectiveness [2]. However, the solubility of sodium monocarboxylates drastically decreases with increasing chain length. A compromise between treatment cost, carbon chain length and water solubility lies, according to Rocca et 
al., in the application of $\mathrm{Pb}\left(\mathrm{C}_{10}\right)_{2}$ (lead decanoate) prepared from a $0.05 \mathrm{~mol} \mathrm{~L}^{-1} \mathrm{NaC}_{10}$ solution [3]. The immersion method proposed by these authors relies on the unassisted formation of lead ions upon immersion in solution. The formation of the carboxylate layer is preceded by the oxidation of the metal by the oxygen dissolved in the aqueous solution and then followed by the precipitation of the lead carboxylate [2-4]. This process takes approximately 24 hours to create a passivating film.

The present work addresses the deposition of $\mathrm{Pb}\left(\mathrm{C}_{12}\right)_{2}$ coatings from a different point of view, namely through electrochemical treatment. Electrochemical treatment of metals can produce metal ions which can precipitate with sodium carboxylates. Metal carboxylates, with aliphatic chains, can in their turn form stable films at the metal surface and may inhibit the corrosion of many metals, including lead but also copper, zinc and magnesium, in aerated aqueous solutions [2-7]. It is expected that the oxidation process could be controlled more directly by electrochemical treatment and more specifically by applying a potential. The first benefit of potential cycling is thus the shortening of the coating process. Another benefit for electrochemical treatment by cyclic voltammetry is the fact that it is a technique which enables one to control and to characterize the layer formed by following the potential and current during the process.

In this work we focus on the deposition of $\mathrm{Pb}\left(\mathrm{C}_{12}\right)_{2}$ as electrochemical measurements with $\mathrm{NaC}_{10}$ were rather irreproducible. In what follows the deposition procedure as well as the ATR-IR and X-ray diffraction measurements, proving the deposition of the layer, will be discussed.

\section{Experimental}

\subsection{Materials}

The preparation of the $0.025 \mathrm{~mol} \mathrm{~L}^{-1}$ sodium dodecanoate solution was done by finely dispersing $0.5008 \mathrm{~g}$ of dodecanoic acid (Fluka, Belgium, 98\%) in $100 \mathrm{~mL}$ of water and by subsequently neutralizing the suspension with a $0.25 \mathrm{~mol} \mathrm{~L}^{-1} \mathrm{NaOH}$ solution. The initial turbidity of the suspension at this point disappeared slowly. To make sure all the acid was 
neutralized, the solution was stirred overnight. $\mathrm{pH}$ measurements showed an average value of $8.91 \pm 0.03$.

A non-corrosive reference solution was made by mixing distilled water and the same amount of $\mathrm{NaOH}$ needed for neutralizing the dodecanoic acid solution in a further stage. This reference solution is thus a $0.025 \mathrm{~mol} \mathrm{~L}^{-1} \mathrm{NaOH}$ water solution.

Following the work of Rocca et al. [3], ASTM D 138-87 solution was used to simulate atmospheric corrosion (148 mg L ${ }^{-1} \mathrm{Na}_{2} \mathrm{SO}_{4}$ (Sigma Aldrich), $138 \mathrm{mg} \mathrm{L}{ }^{-1} \mathrm{NaHCO}_{3}$ (Sigma Aldrich) and $165 \mathrm{mg} \mathrm{L}^{-1} \mathrm{NaCl}$ (Sigma Aldrich)). We refer to this as "ASTM solution" in what follows.

\subsection{Electrochemical instrumentation and techniques}

Electrochemical experiments were performed in a three electrode cell using a saturated calomel reference electrode (SCE) containing two compartments (Radiometer Analytical, France) and a carbon counter electrode. The working electrodes were lead rods encapsulated in epoxy resin (Goodfellow, purity 99.99\%) with an end diameter of $2 \mathrm{~mm}$ exposed to the solution. These were pre-treated by mechanical and electrochemical polishing according to the following procedure: before its first use the electrode surface was roughly polished using a silicon carbide paper of grit 600/P1200 to obtain a fresh surface. Fine polishing was achieved using a polishing cloth covered with alumina powder of $1 \mu \mathrm{m}$ particle size (Buehler, USA) in isopropanol for 1 minute. To remove any adhering $\mathrm{Al}_{2} \mathrm{O}_{3}$ particles the electrode surface was rinsed thoroughly with isopropanol and cleaned in an ultrasonic bath containing a beaker with isopropanol (Branson 3210, USA) for 2 minutes. A last step consisted of polishing the electrode surface on a bare cloth with isopropanol only. A PGSTAT20 potentiostat controlled by GPES 4.9 005 software package running (ECO Chemie, The Netherlands) was used to record voltammetric curves.

The modification of a lead electrode by dodecanoate was performed by recording successive cyclic voltammetric scans ( 5 or 30 scans) in a potential window from -1.3 to $1.5 \mathrm{~V}$ vs SCE with a scan rate of $50 \mathrm{mV} \mathrm{s}^{-1}$ in a $0.025 \mathrm{~mol} \mathrm{~L}^{-1} \mathrm{NaC}_{12}$ solution. After each modification procedure, the electrode was rinsed with distilled water. Prior to each experiment, pure nitrogen was bubbled through the cell solution for 20 minutes. 
The coating analysis was done under polarization conditions, the linear polarization and Tafel extrapolation techniques were used. The polarization experiments were carried out at a scan rate of $1 \mathrm{mV} \mathrm{s}^{-1}$ from -0.25 to $1.3 \mathrm{~V}$ vs $E_{\text {corr }}$. The corrosion potential, $E_{\text {corr, }}$ was determined by a potentiometric measurement (zero current) during $1000 \mathrm{~s}$.

\subsection{ATR-IR and XRD analyses}

ATR-IR and XRD spectroscopic analyses were performed in order to obtain qualitative proof of the deposition of dodecanoate onto the lead surface.

Reflectance spectra were acquired using a Biorad FT-IR spectrometer FTS 575C equipped with a 'Golden Gate' ATR accessory. The latter was fitted with a diamond crystal. The coating covering the electrode surface was measured directly by pressing the electrode against the ATR crystal. The spectra were recorded over the range $4000-600 \mathrm{~cm}^{-1}$ and averaged over 16 scans.

X-ray diffraction data were obtained from an electrode modified with 30 cycles using a Panalytical X-Pert Pro Multipurpose Diffractometer (MPD) equipped with a curved germanium focussing monochromator to produce $\mathrm{CuK \alpha} \alpha_{1}$ radiation $(\lambda=1.5405 \AA)$ and a PIXcel detector. The sample was mounted to receive diffraction in reflection geometry from the surface of the film, which was centred to half-cut the intensity in the direct beam. Data were collected by means of a conventional $\theta-2 \theta$ scan in the $2 \theta$ range $2-40^{\circ}$ with a step-size of $0.0263^{\circ} 2 \theta$ over a period of 80 minutes.

\section{Results and discussion}

\subsection{Electrochemical behaviour of lead in an alkaline solution}

Figure 1 shows the first four scans recorded at a bare lead electrode in the alkaline noncorrosive reference solution (without carboxylates). The first voltammogram (scan 1) shows two well defined oxidation peaks labelled $A_{1}$ (in the potential region from -620 to $-300 \mathrm{mV}$ ) and $\mathrm{A}_{2}$ (600 to $1000 \mathrm{mV}$ ) due to $\mathrm{PbO}$ and $\mathrm{PbO}_{2}$ formation respectively. In addition, a small shoulder $A_{1}{ }^{\prime}$ is observed on the cathodic side of the first anodic process. This process can be 
explained as the formation of a thin $\mathrm{Pb}(\mathrm{OH})_{2}$ film according to the following mechanism [89]:

$\mathrm{Pb}+\mathrm{OH}^{-} \leftrightarrows \mathrm{PbOH}_{\mathrm{ads}}+\mathrm{e}^{-}$

$\mathrm{PbOH}_{\mathrm{ads}}+\mathrm{OH}^{-} \leftrightarrows \mathrm{Pb}(\mathrm{OH})_{2}+\mathrm{e}^{-}$

The $\mathrm{Pb}(\mathrm{OH})_{2}$ film formed mostly dissolves, yielding $\mathrm{Pb}(\mathrm{OH})_{3}{ }^{-}$ions, whereas the remaining $\mathrm{Pb}(\mathrm{OH})_{2}$ transforms into $\mathrm{PbO}$ at a more positive potential than that required for the formation of $\mathrm{Pb}(\mathrm{OH})_{2}$. The mechanism corresponding to this reaction is given below [8]:

$\mathrm{PbOH}_{\mathrm{ads}}+\mathrm{OH}^{-} \leftrightarrows \mathrm{PbO}_{\mathrm{ads}}^{-}+\mathrm{H}_{2} \mathrm{O}$

$\mathrm{PbO}_{\mathrm{ads}}^{-} \leftrightarrows \mathrm{PbO}+\mathrm{e}^{-}$

The oxidation process $A_{1}$ is called the lead dissolution process.

After this process, the electrode becomes passive and the current drops to a lower value and extends over a wide potential range. Within this region, the value of $I_{\text {passivation }}$ is nearly constant and to some extent independent of the applied potential. The second oxidation peak $\mathrm{A}_{2}$ can be explained as the transformation of $\mathrm{PbO}$ to $\mathrm{PbO}_{2}$ according to the following reactions [8]:

$$
\begin{gathered}
3 \mathrm{PbO}+2 \mathrm{OH}^{-} \leftrightarrows \mathrm{Pb}_{3} \mathrm{O}_{4}+\mathrm{H}_{2} \mathrm{O}+2 \mathrm{e}^{-} \\
\mathrm{Pb}_{3} \mathrm{O}_{4}+4 \mathrm{OH}^{-} \leftrightarrows 3 \mathrm{PbO}_{2}+2 \mathrm{H}_{2} \mathrm{O}+2 \mathrm{e}^{-}
\end{gathered}
$$

When the anodic potential is reversed after process $A_{2}$, two reduction processes appear $\left(C_{2}\right.$ in the potential region from 400 to $-400 \mathrm{mV}$ and $C_{1}$ from -760 to $-1300 \mathrm{mV}$ ). It is clear that the process in the potential region from 400 to $-400 \mathrm{mV}$ encloses several reduction reactions. This separation could be explained by the fact that $\mathrm{PbO}_{2}$ would be reduced first to $\mathrm{Pb}_{3} \mathrm{O}_{4}$ and the latter to $\mathrm{PbO}[8]$ :

$3 \mathrm{PbO}_{2}+2 \mathrm{H}_{2} \mathrm{O}+2 \mathrm{e}^{-} \leftrightarrows \mathrm{Pb}_{3} \mathrm{O}_{4}+4 \mathrm{OH}^{-}$ 
Process $\mathrm{C}_{1}$ occurs in the region of the $\mathrm{PbO} / \mathrm{Pb}$ potential [8-10]. This process corresponds to the lead deposition phenomenon.

A change of the voltammetric behaviour is observed during the consecutive scans. This phenomenon can be explained by the fact that the products formed during the potential cycling are adsorbed particles and thus have an influence on the electron transfer at the electrode. The $I_{\text {passivation }}$ between process $\mathrm{A}_{1}$ and $\mathrm{A}_{2}$ no longer remains constant but increases slightly as a function of scan number indicating the growth and thickening of the oxide surface film. After four scans a layer of higher lead oxides is formed blocking the lead surface. Figure 2 shows optical images from the lead surface at various stages in the experiment. The first two are before (a) and after (b) potential cycling in the alkaline reference solution. The red-brown coloured adsorbed species is mixture of lead oxides, $\mathrm{Pb}_{3} \mathrm{O}_{4}$ and $\mathrm{PbO}_{2}[11]$.

\subsection{Electrochemical behaviour of lead in a sodium dodecanoate solution}

When dodecanoic acid is added to the alkaline reference solution, it is expected that the sodium hydroxide neutralises the acid resulting in the formation of sodium dodecanoate. Figure 3 shows the cyclic voltammetry behaviour of $0.025 \mathrm{~mol} \mathrm{~L}^{-1} \mathrm{NaC}_{12}$ at a lead electrode in the potential window from -1.3 to $1.5 \mathrm{~V}$ vs SCE at a scan rate of $50 \mathrm{mV} \mathrm{s}^{-1}$. In the first scan three redox processes are observed, i.e. $\mathrm{A}_{1}, \mathrm{~A}_{1}{ }^{\prime}$ and $\mathrm{C}_{1}$. In comparison with the electrochemical behaviour of lead in the reference solution, $\mathrm{A}_{1}$ and $\mathrm{A}_{1}{ }^{\prime}$ represent the dissolution of lead. The reduction process $\mathrm{C}_{1}$ represents the lead deposition process. From scan 2 , a stable voltammetric signal is observed and this until scan 30 , only the processes $\mathrm{A}_{1}{ }^{\prime}$ and $C_{1}$ are observed. There is no further oxidation process after peak $A_{1}{ }^{\prime}$.

The shoulder $\mathrm{A}_{1}{ }^{\prime}$ has already been described as the dissolution of lead and formation of a thin $\mathrm{Pb}(\mathrm{OH})_{2}$ film according to equation 1 and 2 in the absence of $\mathrm{NaC}_{12}$ (see above). It is at this corresponding potential that, in the presence of $\mathrm{NaC}_{12}$, the formation of the dodecanoate film occurs during the next scans. The dodecanoate ion acts as a ligand for complexation with lead ions, instead of hydroxide in the reference solution. In addition, further oxide formation $\left(\mathrm{A}_{1}\right.$ 
and $\mathrm{A}_{2}$ ) is inhibited in the next scans. Scan 2 only shows a well defined oxidation peak $\mathrm{A}_{1}{ }^{\prime}$ and a reduction process $\mathrm{C}_{1}$. In contrast, in the first scan there is still a competition between hydroxide and dodecanoate adsorption as process $\mathrm{A}_{1}{ }^{\prime}$ as well as $\mathrm{A}_{1}$ appears. This ties in very nicely with our real-time XRD observations of the growth of lead decanoate, where we see the oxidation essentially stop after a couple of hours, after which decreases as it is masked by the decanoate growth [4].

Following the addition of $\mathrm{NaC}_{12}$, the oxidation $\mathrm{A}_{1}{ }^{\prime}$ and reduction $\mathrm{C}_{1}$ reaction represent the lead dissolution/deposition respectively. The carboxylate is adsorbed onto the lead resulting in a blocking of the surface for further oxidation. A first indication of adsorption is the decrease of the lead related redox reactions compared to corresponding processes in Figure 1.

The well developed anodic peak is characteristic of a passivation process. At more positive potentials, the current drops to a low value corresponding to the passive state. Its appearance suggests an active dissolution-passivation transition. The oxidation process is indicative of two processes. First, there is the dissolution of lead and the formation of a soluble lead salt with dodecanoate as the anion. The dissolution of lead in a carboxylate solution can be explained as a series of adsorption reactions involving catalysis by the anion at active surface sites in monatomic steps followed by desorption of the formed soluble salt as follows [12]:

$$
\begin{aligned}
& \mathrm{Pb}+\mathrm{L}_{(\mathrm{ads})}{ }^{-} \leftrightarrows \mathrm{PbL}_{\mathrm{ads}}+\mathrm{e}^{-} \\
& \mathrm{PbL}_{\mathrm{ads}}+\mathrm{L}^{-} \leftrightarrows \mathrm{PbL}_{2(\mathrm{ads})}+\mathrm{e}^{-} \\
& \mathrm{PbL}_{2 \text { (ads) }} \leftrightarrows \mathrm{PbL}_{2(\mathrm{aq})}
\end{aligned}
$$

where $\mathrm{L}^{-}$is dodecanoate.

Secondly, there is precipitation of a salt film $\mathrm{PbL}(\mathrm{s})$ on the electrode surface when the solubility product of the salt is exceeded. This precipitation at the lead electrode blocks the active sites resulting in an inactivation of the surface with respect to a corrosive medium. The formation of the coating described by the dissolution-precipitation mechanism is controlled by the diffusion of the reacting species. This can be demonstrated by showing that the influence of the scan rate on the peak current obeys the Randles-Sevcik equations [13-14]. Accordingly, the influence of the scan rate on the peak current is shown in Figure 4. Both peak current and 
peak potential increase as a function of scan rate. The inset shows that a linear behaviour is observed for $I_{\mathrm{A} 1}$ versus $v^{1 / 2}$, typically for this type of system.

As the voltammetric behaviour is stable from scan 2, it can be stated that the electrochemical coating process is rather fast. This might be expected because the initial step to deposit the dodecanoate on the lead surface is the oxidation of lead. By cycling the potential during the electrochemical experiment, the lead electrode is brought in this oxidation state followed by a reaction with the dodecanoate. In contrast, for the immersion method it takes some hours to deposit the dodecanoate film as the lead ions are generated in another way as described by Rocca [2-3].

\subsection{Spectroscopic characterization of the adsorbed dodecanoate film}

Figure 2 is an optical image of a bare lead electrode (a) and a lead electrode coated with dodecanoate by recording five successive cyclic voltammograms in a potential window from 1.3 to $1.5 \mathrm{~V}$ vs SCE with a scan rate of $50 \mathrm{mV} \mathrm{s}^{-1}$ (c). A clear difference is observed between both, indicating a deposition. Visually, the coated electrode has a slightly dull view.

Infrared spectra were recorded on the following two electrodes: a bare lead electrode (a) and a with dodecanoate modified lead electrode (b) (see Figure 5). The IR spectrum of the coated electrode (Figure 5 (curve b)) shows important characteristic peaks compared to the bare lead electrode (Figure 5 (curve a)). Strong bonds are observed in the region of 1500, 1400 and 930 $\mathrm{cm}^{-1}$ corresponding to the vibrations of the carboxyl, $\mathrm{COO}^{-}$group [15]. More specific, the adsorptions at 1511,1416 and $930 \mathrm{~cm}^{-1}$ are identified as the antisymmetric mode, $v_{\mathrm{a}} \mathrm{COO}^{-}$, symmetric stretching mode, $v_{\mathrm{s}} \mathrm{COO}^{-}$and deformation, $v_{\mathrm{d}} \mathrm{COO}^{-}$. Both $v_{\mathrm{a}}$ and $v_{\mathrm{s}}$ bands appear as doublets characteristic for long chain bivalent metal carboxylates [16-17].

The dodecanoate, or in general the carboxylate group can bond as a bridge between two metal atoms, as a bidentate or monodentate ligand. The separation between $v_{\mathrm{a}}\left(\mathrm{COO}^{-}\right)$and $v_{\mathrm{s}}\left(\mathrm{COO}^{-}\right)$ is often use to characterize the exact bonding [17-19]. Waddington and co-workers [17] concluded earlier that a bidentate structure is indicated when $\Delta v$ is in the vicinity of $100 \mathrm{~cm}^{-1}$ or less and for a bridged ligand the $\Delta v$ has a value near $150 \mathrm{~cm}^{-1}$. The value for $\Delta v$ for dodecanoate deposition is $95 \mathrm{~cm}^{-1}$, characteristic for a bidentate structure shown in the inset of Figure 5. It is clear that the size of lead allows a bonding with the other oxygen of the 
dodecanoate group. Further research is necessary to well define the exact bonding because it is possible that different modes of bonding occur in the structure.

The X-ray diffraction data (Figure 6) shows the presence of crystalline phases, registered by sharp Bragg peaks, superimposed on an amorphous background, which can be attributed to the epoxy resin in which the sample was mounted. The spectrum is mostly due to lead dodecanoate (pattern reference number 00-0090712 in the 2008 database of the International Centre for Diffraction Data, ICDD). The two strongest peaks in the diffraction spectrum at 31.26 and $36.26^{\circ}$ in $2 \theta$, correspond to diffraction from the $\mathrm{Pb}$ substrate beneath the thin lead dodecanoate layer. There is evidence for the presence of litharge $(\mathrm{PbO})$ just as we found in the case of the decanoate grown from sodium decanoate solution [4]. This is registered by the peak at $35.60^{\circ}$, which is close to the 002 peak at $35.74^{\circ}$ reported for synthetic litharge (reference pattern number 00-005-0561 in the ICDD database) and is consistent with the presence of an (001) highly-oriented $\mathrm{PbO}$ layer. A large degree of (001) orientation in the $\mathrm{PbO}$ layer explains the absence of the strongest litharge diffraction peaks at $28.63^{\circ}$ and $31.83^{\circ}$ in our observed spectrum. These are the 101 and 110 reflections, respectively, which would be in-plane reflections for an (001)-oriented film and are not observable in the BraggBrentano reflection geometry of our diffraction experiment. The $0.14^{\circ}$ difference in $2 \theta$-angle between the reported litharge peak and our observation can be explained principally by the height error inherent in not having the $\mathrm{PbO}$ layer at the half-cut beam position as well as the possible effects of strain in this multilayer system.

\subsection{Coating analysis}

The lead corrosion potential after modification by dodecanoate is ca. $120 \mathrm{mV}$ higher than the potential measured at a lead electrode in the absence of dodecanoate at the surface or in the solution. The performance of $\mathrm{NaC}_{12}$ for lead protection is investigated by recording potentiodynamic curves. Figure 7 represents a Tafel plot of bare lead (curve 1) and coated lead (curve 2) in the ASTM solution. The presence of dodecanoate as inhibitor at the lead electrode induces a decrease of the corrosion current density down to $10^{-11}-10^{-12} \mathrm{~A} \mathrm{~cm}^{-2}$, also the passivation current density decreases, while the pitting phenomenon is clearly inhibited at the coated electrode. 


\section{Conclusions}

In this work, we have investigated the electrochemical deposition of lead dodecanoate coatings on lead. The advantage of this method over the more commonly used immersion treatment is the shortening of the coating process and the control one has over the layer formation. The deposition of the carboxylate was successfully achieved by recording successive cyclic voltammetric scans of a lead electrode in a $0.025 \mathrm{~mol} \mathrm{~L}^{-1}$ sodium dodecanoate solution. Results allowed us to reveal the mechanism of the deposition: first part of the lead surface dissolves and forms a soluble lead salt with dodecanoate as the anion. The latter is followed by the precipitation of a salt film $\mathrm{PbL}(\mathrm{s})$ on the electrode surface. The deposition is proven by ATR-IR and X-ray diffraction spectroscopy. Additional Tafel plots of the bare and coated lead electrode in corrosive environments showed that the presence of dodecanoate induces a decrease of the corrosion current density, while also the passivation current density decreases.

\section{Acknowledgments}

S. Van Vlierberghe and V. Vermeersch (Ghent University, Polymer Chemistry and

Biomaterials Research Group) are gratefully acknowledged for the ATR-IR measurements.

\section{References}

1. Costa V, Urban F (2005) Reviews in Conservation 6: 48

2. Rocca E, Steinmetz J (2001) Corros Sci 43:891

3. Rocca E, Rapin C, Mirambet F (2004) Corros Sci 46:653

4. Dowsett M, Adriaens A, Schotte B, Jones G, Bouchenoire L (2009) Surface and Interface Analysis 41:565

5. Hefter GT, North NA, Tan SH (1997) Corrosion 53:657

6. Rocca E, Bertrand G, Rapin C, Labrune JC (2001) J Electroanal Chem 503:133

7. Rocca E, Caillet C, Mesbah A, François M, Steinmetz J (2006) Chem Mater 18:6186

8. Abd El Aal EE, Abd El Wanees S, Abd El Aal A (1993) J Mater Sci 28:2607

9. Abd El Rehim SS, Ali LI, Amin NH, Mohamed NF (1997) Chem monthly 128:245 
10. Wong SM, Abrantes LM (2005) Electrochim acta 51:619

11. Merck Index, 1996, $12^{\text {th }}$ edition, pp 5452

12. Abd-El Rehim SS, Amin NH, Ali LI, Mohamed NF (1998) J Chem Technol Biotechnol $72: 197$

13. Randles JB (1948) Trans Faraday Soc 44:327

14. Sevick A (1948) Collect Czech Chem Commun 13: 349

15. Ellis HA, White NA, Hassan I, Ahmad R (2002) J Mol Struct 642:71

16. Mesubi MA (1961) J Mol Struct 61

17. Alcock NW, Tracy VM, Waddington TC (1976) J Chem Soc Dalton Trans 2243

18. Nakamoto K, Fujeta F, Kobayashi M (1957) J Am Chem soc 79:4909

19. Patil KC, Chandrashekhar GV, George MV, Rao CNR (1967) Can J Chem 46:257 


\section{Figure captions}

Figure 1. Current-potential curves recorded at a lead electrode in a $0.025 \mathrm{~mol} \mathrm{~L}^{-1} \mathrm{NaOH}$ solution in the absence dodecanoic acid at a scan rate of $50 \mathrm{mV} \mathrm{s}^{-1}$ and a temperature of $298.0 \mathrm{~K}$ as a function of scan number. The first four scans are shown (scan 1: , scan 2: , scan 3: ...... and scan 4:

Figure 2. Optical images of a bare lead electrode (a), a lead electrode after potential cycling in an alkaline reference solution (b) and a lead electrode coated with dodecanoate (c).

Figure 3. Current-potential curve recorded at a lead electrode in a $0.025 \mathrm{~mol} \mathrm{~L}^{-1} \mathrm{NaC}_{12}$ water solution: scan 1 (1) and scan 2-30 (2).

Figure 4. Current-potential curve recorded at a dodecanoate coated lead electrode in a 0.025 mol L ${ }^{-1} \mathrm{NaC}_{12}$ water solution at different scan rates: 20 (1), 50 (2), 80 (3), 160 (4), 320 (5) and 500 (6) $\mathrm{mV} \mathrm{s}^{-1}$. Inset: Relationship between the peak current (I) and square root of the scan rate for process $\mathrm{A}_{1}\left(\mathrm{I}_{\mathrm{A} 1}\right)$ and the passive region ( $\left.\mathrm{I}_{\text {passivation }}\right)$.

Figure 5. ATR-IR spectra of a bare lead electrode (a) and a lead electrode coated with dodecanoate (b). Inset: Mode of bonding.

Figure 6. X-ray diffractogram from an electrode modified with 30 cycles showing the structure of lead dodecanoate overlaid on the lead substrate. Evidence for litharge $(\mathrm{PbO})$ is also found.

Figure 7. Potentiodynamic curves of bare lead (1) and coated lead (2) in an ASTM solutions. 


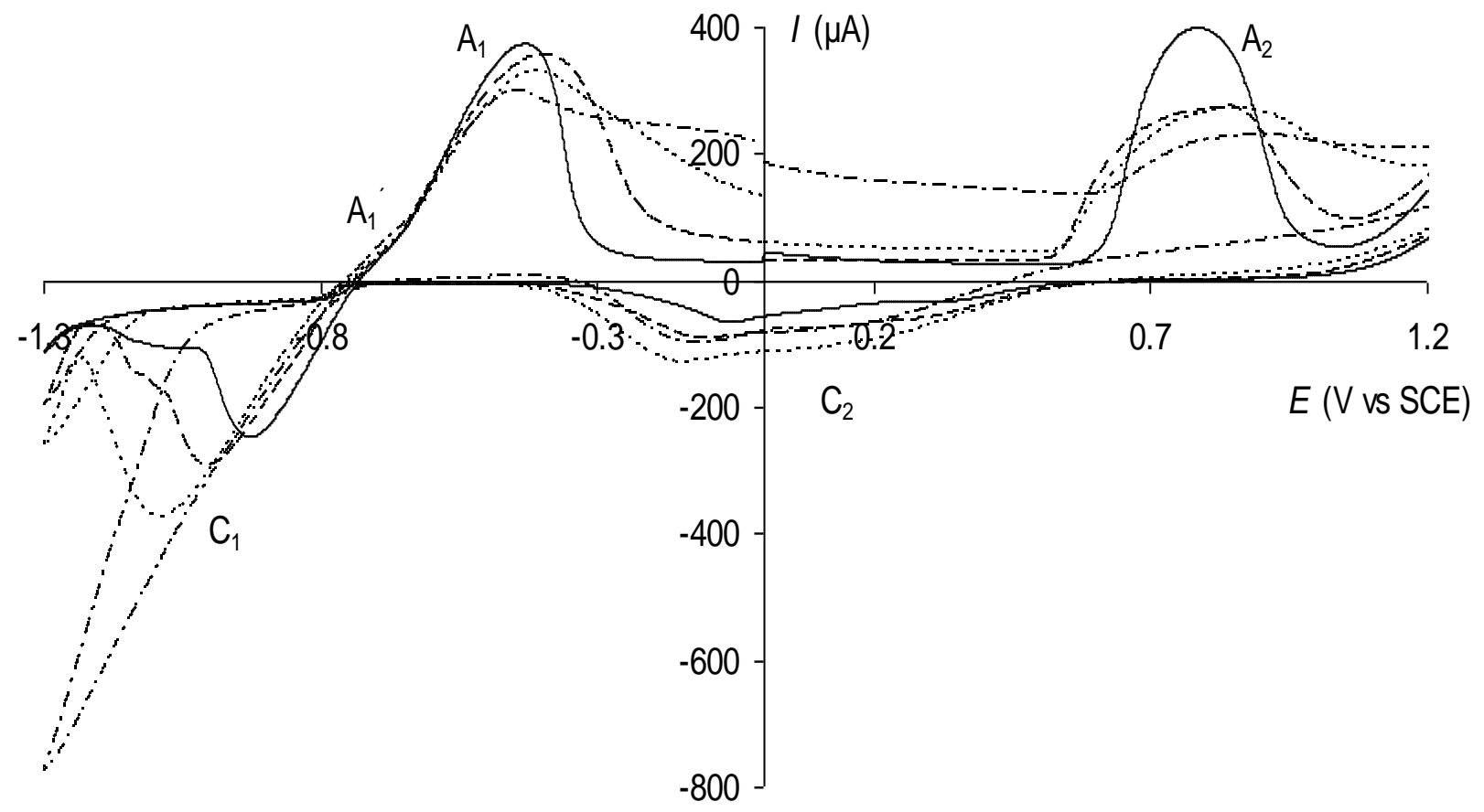

Figure 1
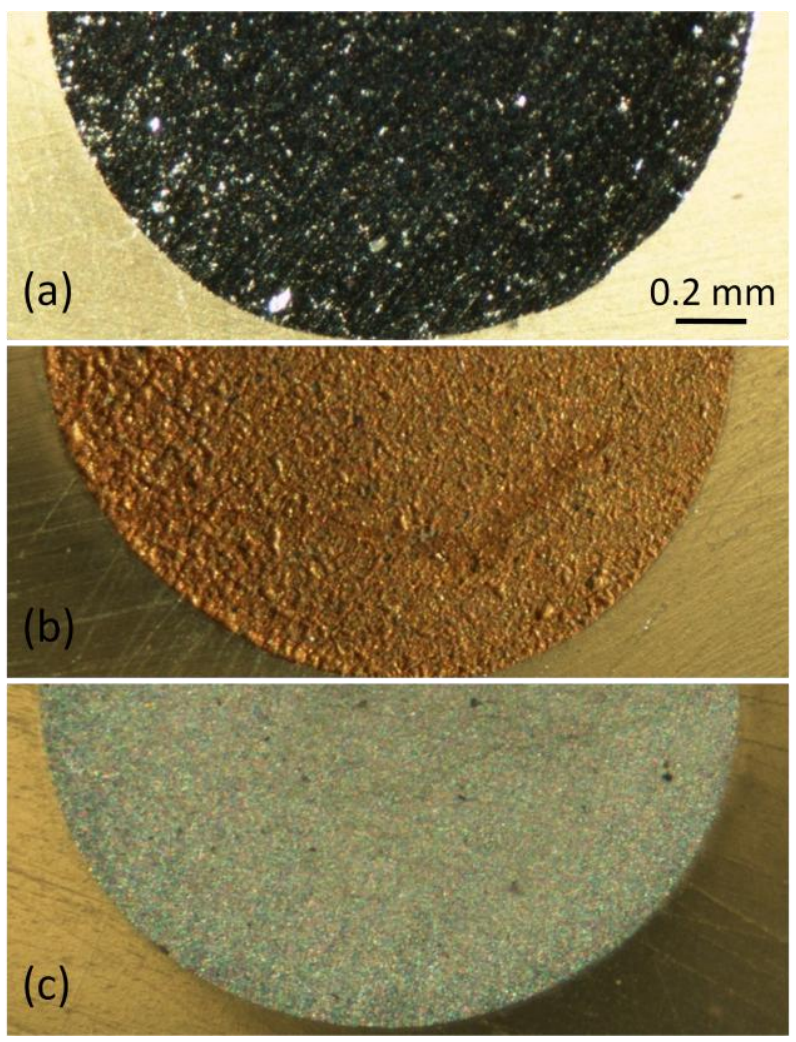

Figure 2 


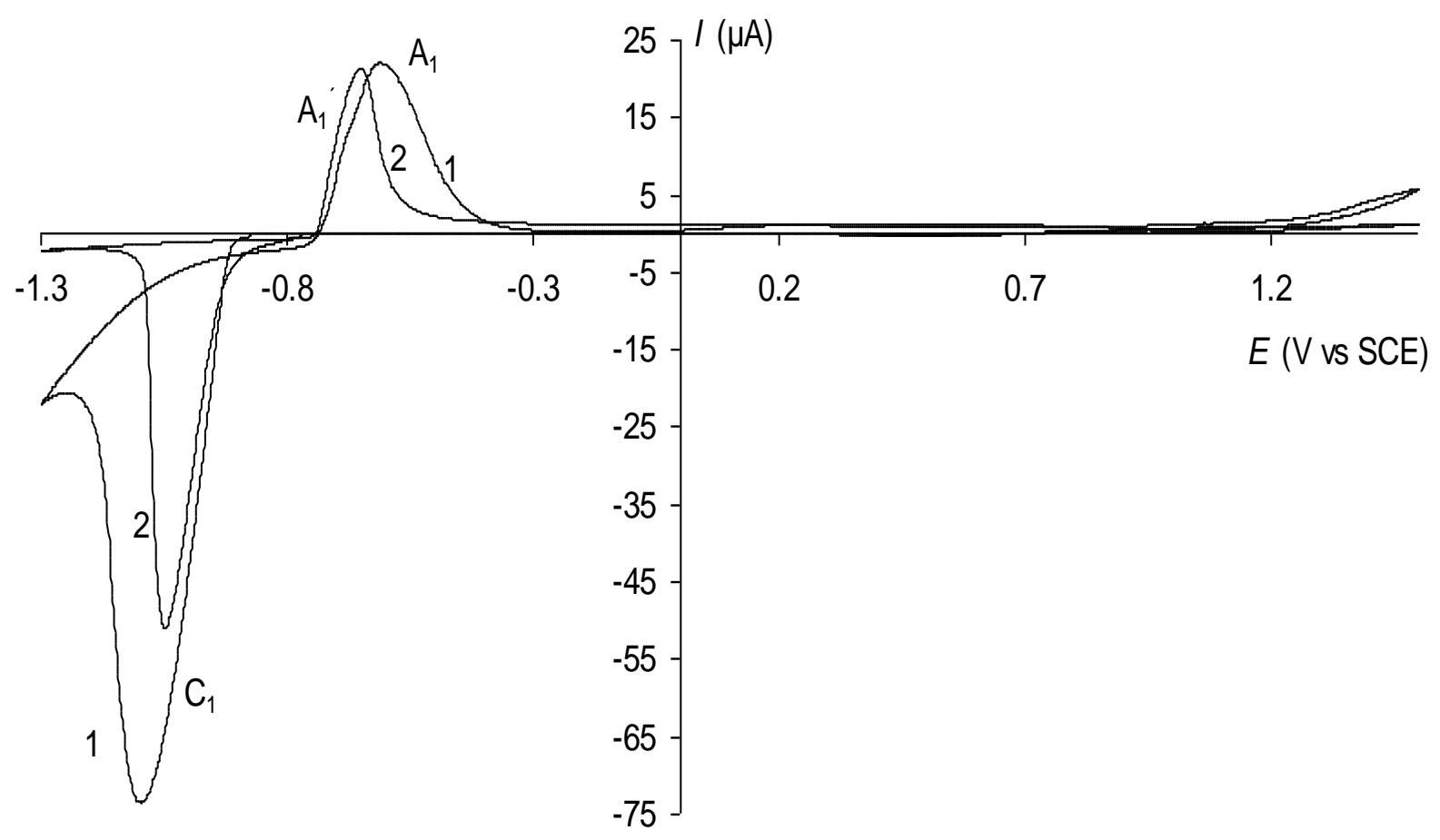

Figure 3

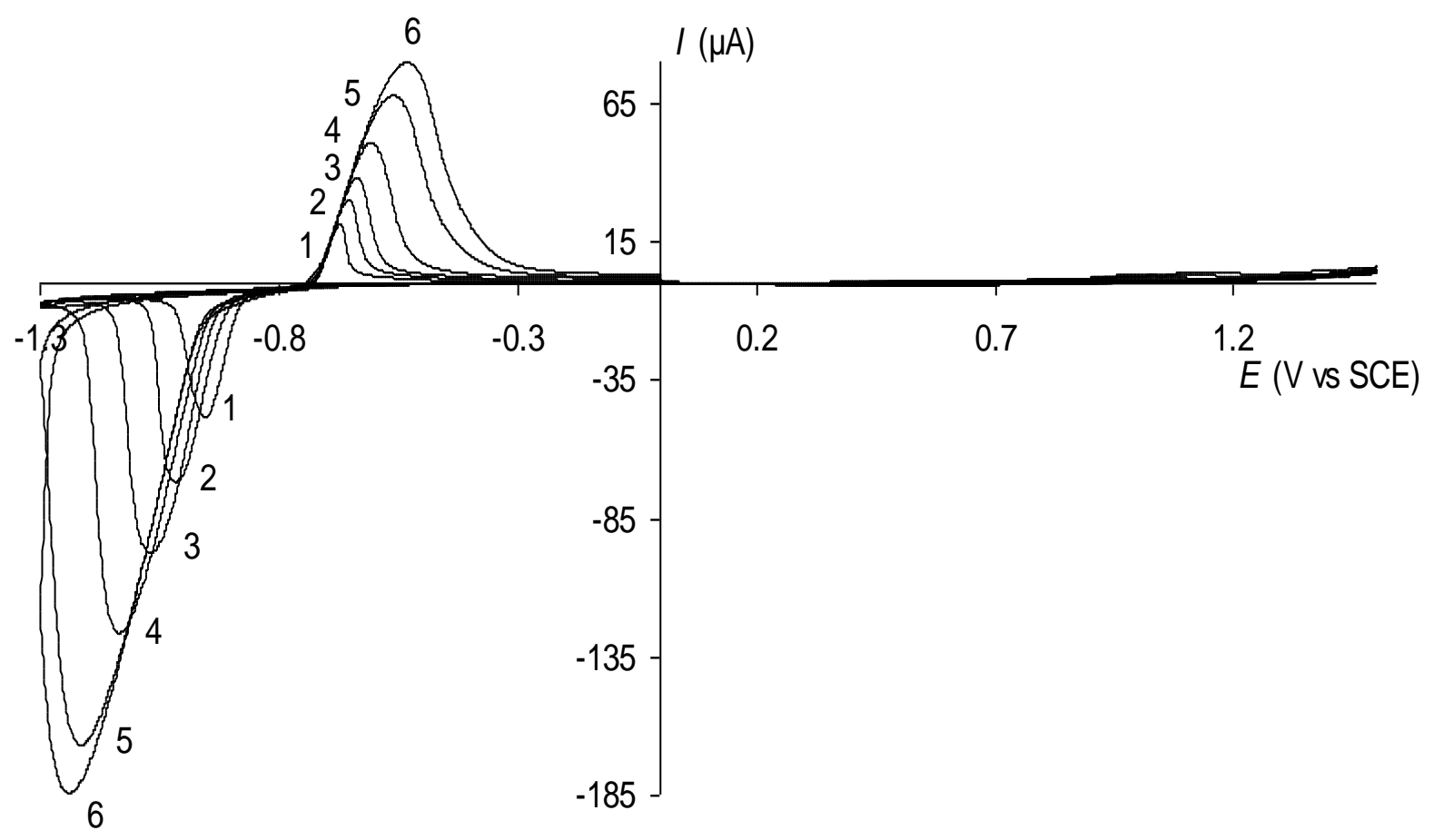

Figure 4 


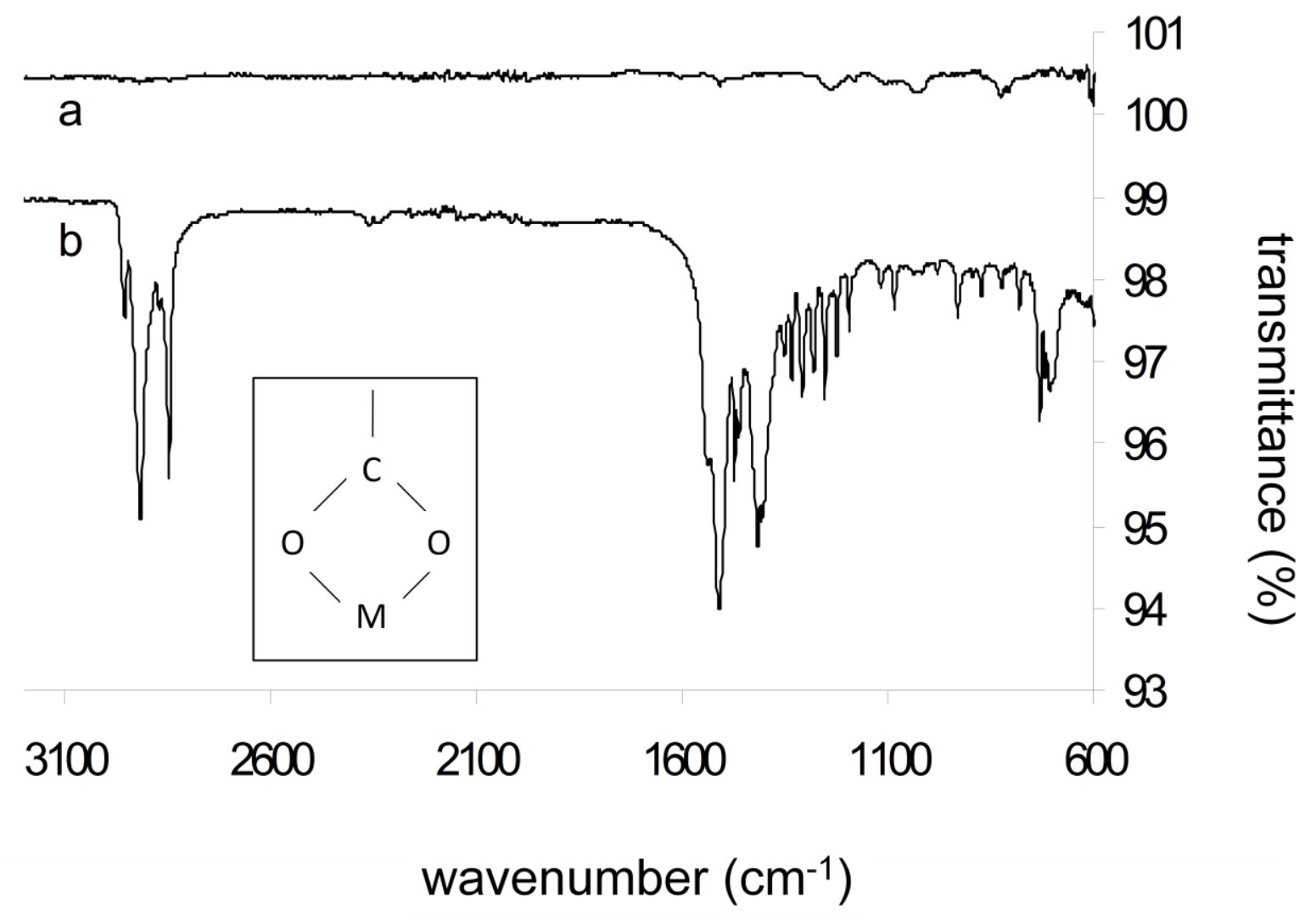

Figure 5

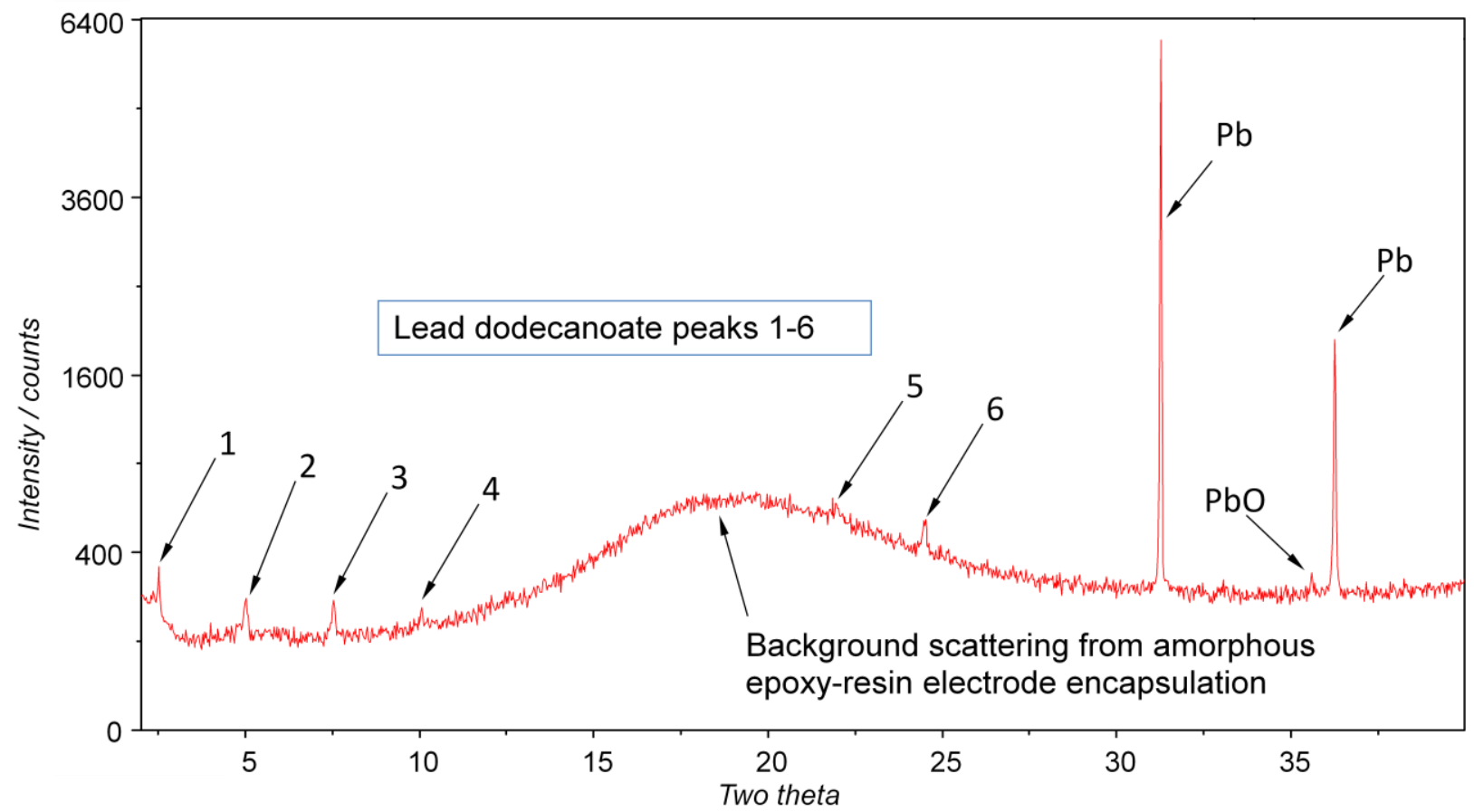

Figure 6 


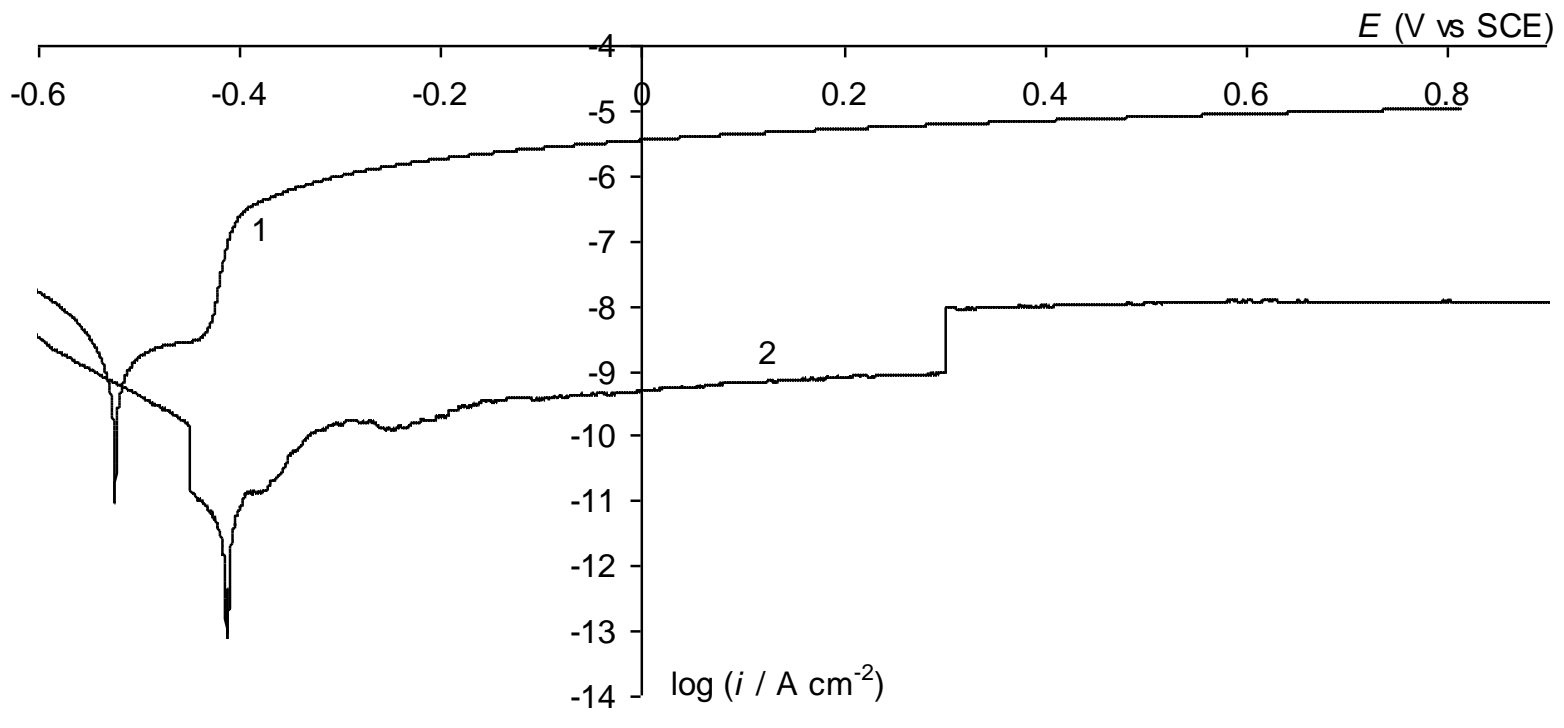

Figure 7 